Case report

\title{
ST elevation myocardial infarction caused by coronary slow flow: Case report and brief review of the literature
}

\author{
Adnan Dogan *, Muhammed Oylumlu, Celal Kilit, Mehmet Özgeyik \\ Dumlupinar University School of Medicine, Department of Cardiology, Kutahya, Turkey
}

\section{A R T I C L E I N F O}

\section{Article history:}

Received 24 October 2015

Accepted 15 November 2015

Available online 26 November 2015

\section{Keywords:}

Coronary slow flow

Electrocardiography

Myocardial infarction

\begin{abstract}
A B S T R A C T
Coronary Slow Flow Phenomenon (CSFP) is an angiographic phenomenon in which vessel opacification is delayed without any evidence of obstructive epicardial coronary disease. We aim to present, in this paper, extremely slow coronary flow along with its severe clinical manifestation. A 47-year-old male patient was admitted to our emergency department with ST elevation myocardial infarction caused by coronary slow flow. Oral Acetylsalicylic acid, nebivolol and atorvastatin therapy successfully resulted in complete resolution of his symptoms during the 18-month observation.

(C) 2015 The Society of Cardiovascular Academy. Production and hosting by Elsevier B.V. All rights reserved. This is an open access article under the CC BY-NC-ND license (http://creativecommons.org/licenses/by-nc-nd/4.0/).
\end{abstract}

\section{Introduction}

The Coronary Slow Flow Phenomenon (CSFP), an angiographic phenomenon first described by Tambe et al. in 1972, refers to the slow movement of contrast agents in the coronary arteries without significant stenosis or myocardial bridge. ${ }^{1}$ The Thrombolysis in Myocardial Infarction (TIMI) frame count, a reproducible index of coronary flow, functions as the quantitative measurement of coronary slow flow. ${ }^{2}$ More specifically, it is a numerical representation of cine frames which are necessary for the contrast agents to reach a pre-specified distal coronary artery landmark. The process is continuous with a correction through normalization of the left anterior descending artery (LAD). The corrected TIMI frame count (CTFC) is the division of the absolute TIMI frame count in the LAD by 1.7. The CSFP phenomenon is characterized by CTFC $>2$ standard deviations from normal published range $(21 \pm 3) .^{2}$ It has been reported that $1-5.5 \%$ of patients who undergo coronary angiography experience CSFP. ${ }^{3}$ However, the pathophysiology of CSFP has not been comprehensively discerned. In this paper, we present a rare case of STEMI caused by coronary slow flow, which might help us to understand better the CSFP.

Case

A 47-year-old man who complained of chest pain spreading towards his shoulder, the pain having begun nearly an hour prior, was admitted into our emergency department. His blood pressure was 110/

\footnotetext{
* Corresponding author at: Dumlupinar University, Department of Cardiology, 43000 Kutahya, Turkey. Tel.: + 905072136611 ; fax: +90 3742316673.

E-mail address: doganadnan01@gmail.com (A. Dogan).

Peer review under responsibility of The Society of Cardiovascular Academy.
}

$75 \mathrm{~mm} \mathrm{Hg}$, his heart rate was 52 beats/min, and his cardiopulmonary examination was normal. His electrocardiogram showed ST elevation in leads V1-4 (Fig. 1A). Then, he was immediately taken to the laboratory for coronary angiography. There was no significant stenosis, coronary vasospasm or myocardial bridge in coronary angiography. Further, intracoronary nitro-glycerine fusion was performed to exclude vasospastic angina. However, no change in ST elevation was observed. On the other hand, advanced-degree slow flow was observed in the LAD and right coronary artery (RCA). The TIMI frame-count method was used to measure the degree of slow flow. The CTFCs were observed to be 52 frames for the left anterior descending coronary artery (Fig. 2A) and 35 frames for the RCA (Fig. 2B). After about $30 \mathrm{~min}$, the patient's chest pain had disappeared completely; ST elevation improved (Fig. 1B); and Troponin I was slightly elevated (Troponin I $0.24 \mu \mathrm{g} / \mathrm{L}$ (normal range, $0.010-0.023 \mu \mathrm{g} / \mathrm{L}$ )). In terms of lipid profile, the findings were as follows: total cholesterol: $182 \mathrm{mg} / \mathrm{dL}$, LDL: $109 \mathrm{mg} / \mathrm{dL}, \mathrm{HDL}: 35$ $\mathrm{mg} / \mathrm{dL}$, and TG: $192 \mathrm{mg} / \mathrm{dL}$. Other biochemical values were normal, his body mass index was in the normal range, and there were no cardiac risk factors other than smoking. Two-dimensional echocardiography showed normal left ventricle function and no wall motion abnormalities. Acetylsalicylic acid $300 \mathrm{mg}$, nebivolol $5 \mathrm{mg}$ and atorvastatin $20 \mathrm{mg}$ were started. The patient was discharged without chest pain after four days with a prescription of acetylsalicylic acid $100 \mathrm{mg}$, nebivolol $5 \mathrm{mg}$ and atorvastatin $20 \mathrm{mg}$. There was no complaint reported during the 18-month period after discharge.

\section{Discussion}

Recurrent chest pain is a commonly observed symptom among patients with CSFP. ${ }^{4}$ Although it is rare, CSFP may also lead to lifethreatening situations such as ST elevation myocardial infarction 


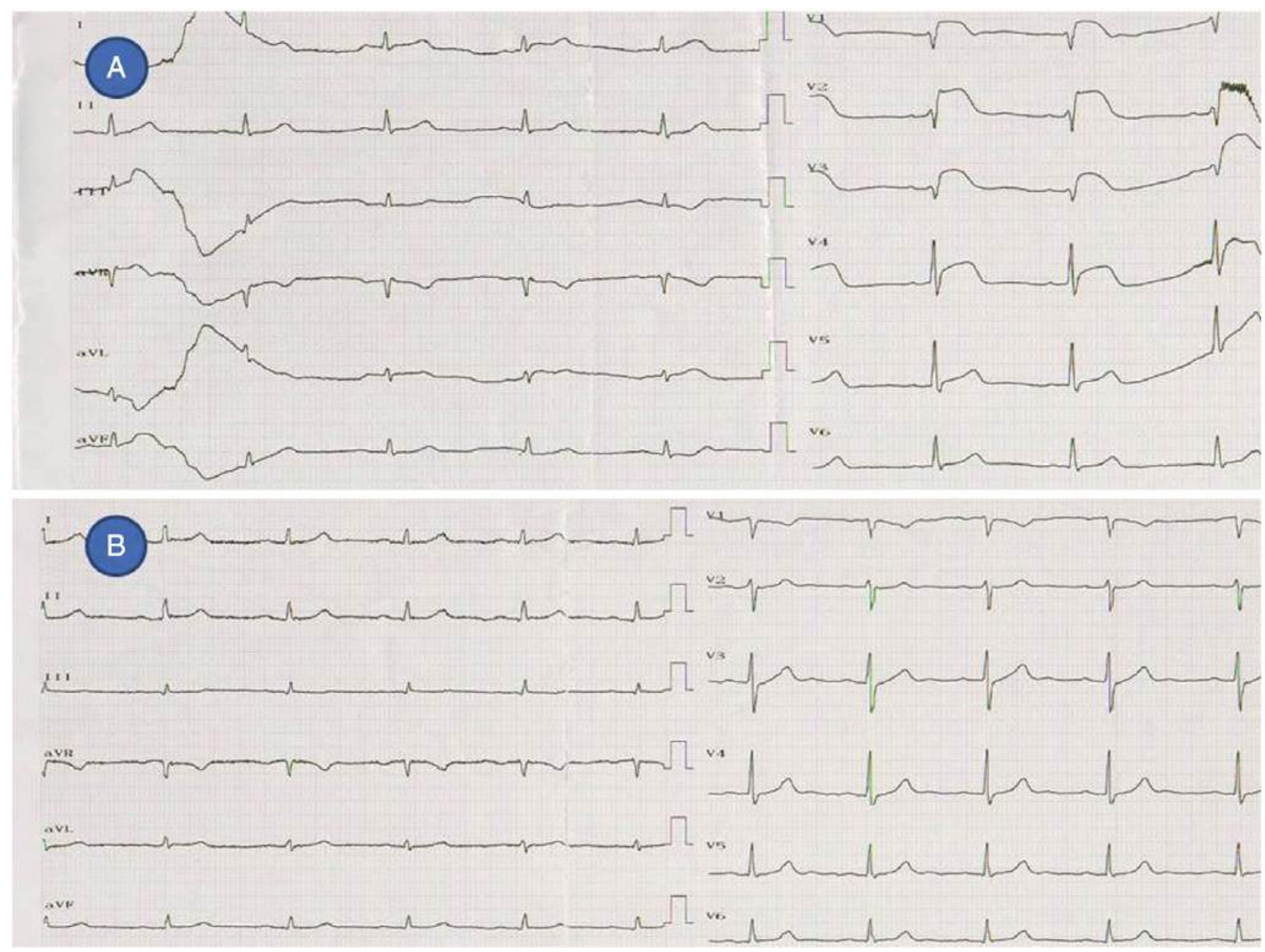

Fig. 1. The electrocardiogram shows ST elevation in leads V1-4 during presence of chest pain (A). ST elevation improved after disappearance of chest pain (B).

(STEMI), ventricular arrhythmias, and sudden cardiac death. ${ }^{5-10}$ Recently, a patient presented as having acute coronary syndrome reportedly illustrated an association between CSFP and a new onset of intermittent left bundle branch block (LBBB). ${ }^{11}$ Also, Sunbul et al. ${ }^{12}$ suggested that slow coronary flow might lead to ST segment elevation in the exercise stress test.

Although different theories have been posited regarding the causes of CSFP, research has not been able to discern comprehensively its pathogenesis. In a variety of researches, small vessel disease, endothelial dysfunction, subclinical atherosclerosis, inflammation, and anatomic properties of coronary arteries have been reported as existing in association with CSFP. Among these, small vessel dysfunction is one of the most typical of the pathogenesis of CSFP. ${ }^{13}$ In an effort to confirm this hypothesis, Beltrame et al. suggested that fibromuscular hyperplasia, medial hypertrophy, myointimal proliferation, endothelial edema, and the thickening as well as the degeneration of the coronary micro-vessels correspond with the phenomenon. ${ }^{14}$ Therefore, it is perhaps more fitting to suggest that the coronary microcirculation might be a result of the coexistence of structural and functional abnormalities. In a variety of cases, patients with CSFP were reported to have increased levels of plasma homocysteine, increased endothelin-1 release and reduced nitric oxide bioactivity, which indicated impaired endothelial function. $^{3,15-18}$ CSFP patients have metabolic syndrome more frequently. ${ }^{19}$ As a result of the use of IVUS technique and flow rate measurements, diffuse intimal thickening, widespread calcification along the coronary vessel wall, and non-obstructive atheromatous coronary changes were reported among patients with $\mathrm{CSFP}^{20}$ Based on the data presented here, it can be argued that CSFP might reflect diffuse, nonobstructive atherosclerotic disease of epicardial vessels together with microvascular disease. Moreover, elevated plasma concentration of high-sensitivity C-reactive protein and interleukin-6 were documented among CSFP patients. ${ }^{21}$ In a similar vein, higher levels of plasma-soluble adhesion molecules such as intercellular adhesion molecule-1, vascular cell adhesion molecule- 1 and E-selectin were reported to exist in relation to coronary slow flow. ${ }^{22}$ Red cell distribution width and serum uric acid levels, among other inflammatory markers, were studied in association with CSFP patients. ${ }^{23,24}$ In endothelial dysfunction, abnormalities in inflammatory parameters can possibly be an indicator; both of these contribute to coronary slow flow. Shao-Ping et al..$^{25}$ demonstrated the existence of CSFP in relation to higher tortuosity and more distal branches in coronary arteries. Thus, certain anatomic properties of coronary arteries could be alleged to have an effect on disturbed coronary flow and endothelial damage, therefore resulting in CSFP.

Treatment for CSFP has not yet been clearly defined, but several drugs have proven to be effective at various levels. So far, pharmacological therapy for CSFP has not been executed on a large scale. Certain small studies have presented evidence regarding the drugs. In some studies, dipyridamole, mibefradil and nitroglycerine have been used for the treatment of CSFP. ${ }^{19,26}$ Statins present certain benefits for CSFP patients, partially owing to their anti-inflammatory properties. ${ }^{27}$ Nebivolol not only can improve endothelial function but also can remedy symptoms considerably; therefore, the drug enhances the 


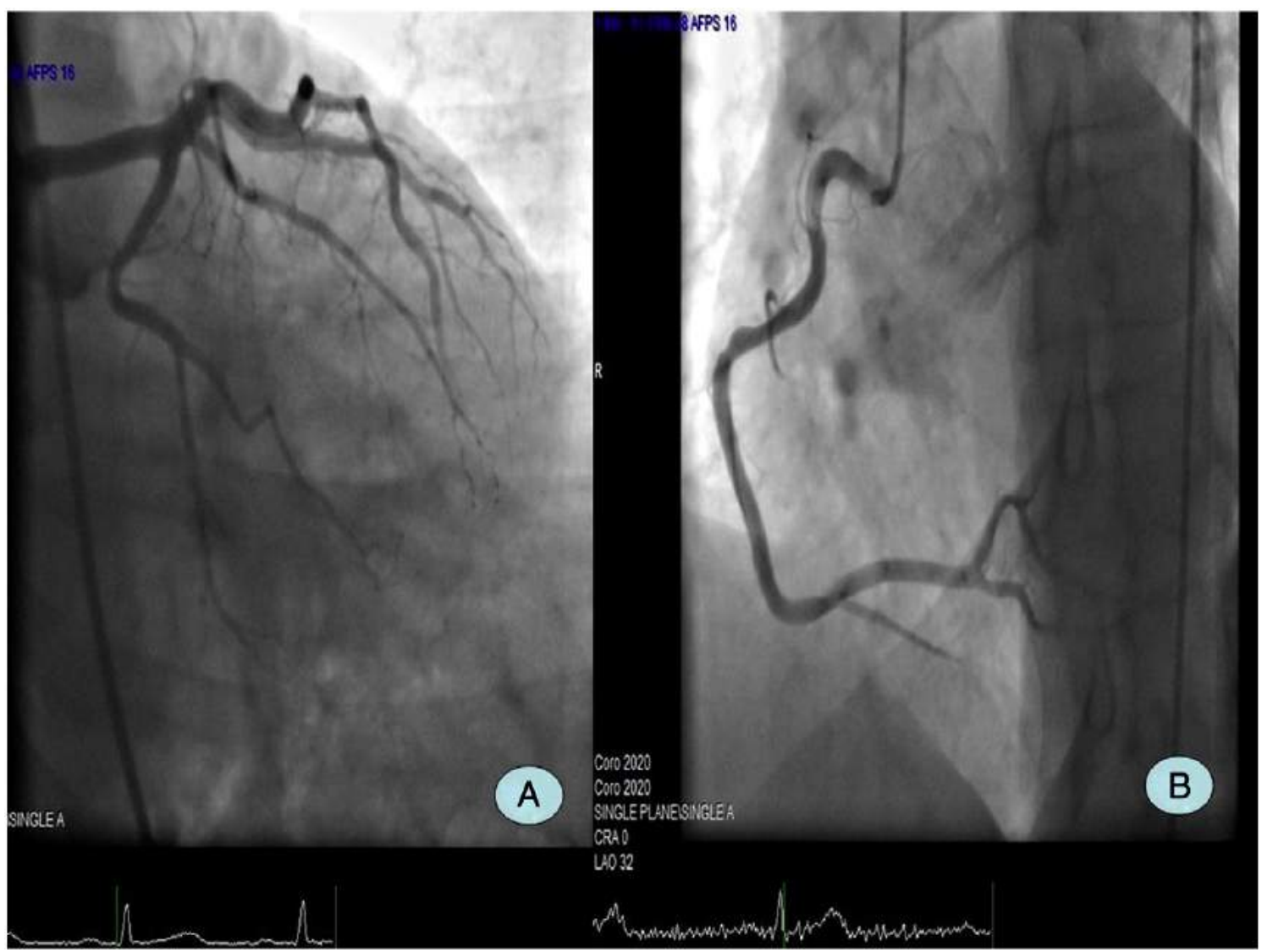

Fig. 2. Coronary angiogram reveals no significant stenosis, together with coronary slow flow in LAD (A) and RCA (B).

quality of life among CSFP patients. ${ }^{28-30}$ Moreover, it might serve as a beta-receptor blocker and, due to increased nitric oxide release, result in endothelium-dependent vasodilatation. ${ }^{28}$

\section{Conclusion}

Slow flow might sound like a minor condition; however, it can result in such a fatal condition as STEMI. With proper treatment, on the other hand, symptoms are reduced. In conclusion, we recommend that CSFP be considered in the etiology of chest pain with ST elevation.

\section{Conflict of interest}

The authors declare that they have no conflict of interest.

\section{References}

1. Tambe AA, Demany MA, Zimmerman HA, et al. Angina pectoris and slow flow velocity of dye in coronary arteries. A new angiographic finding. Am Heart J 1972;84: 66-71.

2. Gibson CM, Cannon CP, Daley WL, et al. TIMI frame count: a quantitative method of assessing coronary artery flow. Circulation 1996;93:879-888.

3. Chaudhry MA, Smith M, Hanna EB, Lazzara R. Diverse spectrum of presentation of coronary slow flow phenomenon: a concise review of the literature. Cardiol Res Pract 2012;2012:383181. http://dx.doi.org/10.1155/2012/383181.

4. Beltrame JF, Limaye SB, Horowitz JD. The coronary slow flow phenomenon - a new coronary microvascular disorder. Cardiology 2002;97:197-202.

5. Celik T, Iyisoy A, Kursaklioglu H, Yuksel C, Turhan H, Isik E. ST elevation during treadmill exercise test in a young patient with slow coronary flow: a case report and review of literature. Int J Cardiol 2006;112:e1-e4.

6. Tatli E, Yildirim T, Aktoz M. Does coronary slow flow phenomenon lead to myocardial ischemia? Int J Cardiol 2009;131:e101-e102.

7. Kapoor A, Goel PK, Gupta S. Slow coronary flow-a cause for angina with ST segment elevation and normal coronary arteries. A case report. Int J Cardiol 1998;67:257-261.

8. Sen T. Coronary slow flow phenomenon leads to ST elevation myocardial infarction. Korean Circ J 2013;43(3):196-198.
9. Saya S, Hennebry TA, Lozano P, et al. Coronary slow flow phenomenon and risk for sudden cardiac death due to ventricular arrhythmias: a case report and review of literature. Clin Cardiol 2008;31:352-355.

10. Amasyali B, Turhan $\mathrm{H}$, Kose $\mathrm{S}$, et al. Aborted sudden cardiac death in a 20-year-old man with slow coronary flow. Int J Cardiol 2005;109(3):427-429.

11. Acikel S, Bozkaya OA, Akdemir R. The relationship between intermittent left bundle-branch block and slow coronary flow in a patient presenting with acute coronary syndrome. Blood Coagul Fibrinolysis 2010;21(6):595-597.

12. Sunbul M, Erdogan O, Sari I. Asymptomatic ST segment elevation in the recovery phase of the exercise stress test due to slow coronary flow. Postep Kardiol Inter 2014;10(35):53-56 [1].

13. Altas Y, Kurtoglu E, Yaylak B, et al. The relationship between eosinophilia and slow coronary flow. Ther Clin Risk Manag 2015;11:1187-1191.

14. Mosseri M, Yarom R, Gotsman MS, et al. Histologic evidence for small-vessel coronary artery disease in patients with angina pectoris and patent large coronary arteries. Circulation 1986;74:964-972.

15. Yetkin E, Turhan H, Erbay AR, Aksoy Y, Senen K. Increased thrombolysis in myocardial infarction frame count in patients with myocardial infarction and normal coronary arteriogram: a possible link between slow coronary flow and myocardial infarction. Atherosclerosis 2005;181:193-199.

16. Mangieri E, Tanzilli G, De Vincentis G, et al. Slow coronary flow and stress myocardial perfusion imaging. Different patterns in acute patients. J Cardiovasc Med (Hagerstown) 2006;7:322-327.

17. Demirkol MO, Yaymaci B, Mutlu B. Dipyridamole myocardial perfusion single photon emission computed tomography in patients with slow coronary flow. Coron Artery Dis 2002;13:223-229.

18. Kurtoglu N, Akcay A, Dindar I. Usefulness of oral dipyridamole therapy for angiographic slow coronary artery flow. Am J Cardiol 2001;87:777-779.

19. Yilmaz H, Demir I, Uyar Z. Clinical and coronary angiographic characteristics of patients with coronary slow flow. Acta Cardiol 2008;63:579-584.

20. Cin VG, Pekdemir H, Camsar A, et al. Diffuse intimal thickening of coronary arteries in slow coronary flow. Jpn Heart J 2003;44:907-919.

21. Li JJ, Qin XW, Li ZC, et al. Increased plasma C-reactive protein and interleukin-6 concentrations in patients with slow coronary flow. Clin Chim Acta 2007;385:43-47.

22. Turhan H, Saydam GS, Erbay AR, et al. Increased plasma soluble adhesion molecules; ICAM-1, VCAM-1, and E-selectin levels in patients with slow coronary flow. Int J Cardiol 2006;108:224-230.

23. Kalay N, Aytekin M, Kaya MG, et al. The relationship between inflammation and slow coronary flow: increased red cell distribution width and serum uric acid levels. Turk Kardiyol Dern Ars 2011;39:463-468.

24. Yildiz A, Yilmaz R, Demirbag R, et al. Association of serum uric acid level and coronary blood flow. Coron Artery Dis 2007;18:607-613. 
25. Niea Shao-Ping, Wanga Xiao, Genga Li-Li, et al. Anatomic properties of coronary arteries are correlated to the corrected thrombolysis in myocardial infarction frame count in the coronary slow flow phenomenon. Coron Artery Dis 2012 May;23(3) 174-180.

26. Beltrame JF, Turner SP, Leslie SL, et al. The angiographic and clinical benefits of mibefradil in the coronary slow flow phenomenon. J Am Coll Cardiol 2004;44:57-62.

27. Li JJ, Zheng X, Li J. Statins may be beneficial for patients with slow coronary flow syndrome due to its antiinflammatory property. Med Hypotheses 2007;69:333-337.
28. Gunes Y, Tuncer M, Guntekin U, et al. Regional functions of the left ventricle in patients with coronary slow flow and the effects of nebivolol. Ther Adv Cardiovasc Dis 2009;3:441-446.

29. Fragasso G. Nebivolol in patients with coronary slow flow: the right drug for the right case? Anadolu Kardiyol Derg 2009;9:296-297.

30. Albayrak S, Ordu S, Yuksel H, et al. Efficacy of nebivolol on flow-mediated dilation in patients with slow coronary flow. Int Heart J 2009;50:545-553. 